\title{
Bone Mineral Density and Body Composition before and during Treatment with Gonadotropin-Releasing Hormone Agonist in Children with Central Precocious and Early Puberty*
}

\author{
ANNEMIEKE M. BOOT, SABINE M. P. F. DE MUINCK KEIZER-SCHRAMA, \\ HUIBERT A. P. POLS, ERIC P. KRENNING, AND STENVERT L. S. DROP \\ Department of Pediatrics, Division of Endocrinology, Sophia Children's Hospital; and Department of \\ Internal Medicine and Department of Nuclear Medicine, Dijkzigt Hospital, Erasmus University, 3015 \\ GJ Rotterdam, The Netherlands
}

\begin{abstract}
Major changes in bone mineral density (BMD) and body composition occur during puberty. In the present longitudinal study, we evaluated BMD and calculated volumetric BMD [bone mineral apparent density (BMAD)], bone metabolism, and body composition of children (32 girls and 2 boys) with central precocious and early puberty before and during treatment with $\mathrm{GnRH}$ agonist $(\mathrm{GnRH})$. Patients were studied at baseline and during treatment for 6 months $(\mathrm{n}=34), 1 \mathrm{yr}$ $(\mathrm{n}=33)$, and $2 \mathrm{yr}(\mathrm{n}=16)$. Lumbar spine and total body BMD and body composition were measured with dual-energy x-ray absorptiometry. The variables were compared with age- and sex-matched reference values of the same population and expressed as SD score (SDS). Bone age was assessed. Serum calcium, phosphate, alkaline phosphatase, osteocalcin, the carboxyterminal propeptide of type I collagen (PICP), cross-linked telopeptide of collagen I (ICTP), 1,25 dihydroxyvitamin $\mathrm{D}$ and urinary hydroxyproline/creatinine, and calcium/creatinine ratios were measured.
\end{abstract}

Mean lumbar spine BMD SDS was significantly higher than zero at baseline $(P<0.02)$ and did not differ from normal, after $2 \mathrm{yr}$ of treatment. Mean spinal BMAD SDS and total body BMD SDS were not significantly different from zero at baseline and had not changed significantly after $2 \mathrm{yr}$ of treatment. During therapy, fat mass and percentage body fat SDS increased, whereas lean tissue mass SDS decreased. Mean lumbar spine BMD and BMAD and total body BMD SDS, calculated for bone age, were all lower than zero at baseline (BMD $P<0.001$ and BMAD $P<0.05$ ) and also after 2 yr treatment (respectively, $P<0.001, P<0.05$, and $P<0.01$ ). Biochemical bone parameters were significantly higher than prepubertal values at baseline, and they decreased during treatment. In conclusion, patients with central precocious and early puberty had normal BMD for chronological age but low BMD for bone age, after $2 \mathrm{yr}$ of treatment with GnRH. Bone turnover decreased during treatment. Changes in body composition resembled those seen in patients with GH deficiency. (J Clin Endocrinol Metab 83: 370-373, 1998)
$\mathrm{D}$ URING puberty, bone mineral density (BMD) and height increase, and body composition changes markedly (14). In central precocious puberty, the hythalamus-pituitary-gonadal axis is activated before the age of $8 \mathrm{yr}$ in girls and before the age of $9 \mathrm{yr}$ in boys. Precocious puberty is associated with premature and rapid skeletal maturation, leading to decreased final height, compared with target height, in most patients (5, 6). GnRH agonist (GnRH) can be supplied to arrest pubertal development to improve final height and avoid psychosocial problems (7-9). In children with central early puberty, final adult height may be slightly improved with GnRH treatment (9). In the present study, both children with central precocious puberty and children with central early puberty who started treatment with GnRH were included. Treatment with GnRH causes a decline in gonadal sex steroids, which may affect BMD, bone metabolism, and body composition. Some studies in children with central precocious puberty showed a decrease of BMD after 6 and 12 months of treatment with $\operatorname{GnRH}(10,11)$; another study reported no change during treatment (12). In

Received August 8, 1997. Revision received October 17, 1997. Accepted October 27, 1997.

Address all correspondence and requests for reprints to: A. M. Boot, Division of Endocrinology, Sophia Children's Hospital, dr Molewaterplein 60, 3015 GJ Rotterdam, The Netherlands. E-mail: boot@alkg.azr.nl.

* This work was supported by Novo Nordisk Farma BV. women with endometriosis and in elderly men with benign prostatic hyperplasia, BMD decreased, and biochemical markers of bone turnover increased during treatment with $\mathrm{GnRH}$ $(13,14)$.

The aim of the present study was to investigate BMD, bone metabolism, and body composition of children with central precocious or early puberty $(\mathrm{CPP})$ before and during treatment with GnRH.

\section{Patients}

\section{Subjects and Methods}

At diagnosis all patients had a history of increased growth velocity, girls had breast development Tanner stage 2 or more and boys genital development Tanner stage 2 or more and testis volume $4 \mathrm{~mL}$ or more, bone age was advanced more than $1 \mathrm{yr}$ beyond chronological age, and a GnRH-stimulated serum LH concentration greater than $10 \mathrm{IU} / \mathrm{L}$. Thirty-four patients participated in the study. Twenty-three girls and 2 boys had true idiopathic central precocious puberty. Seven girls had idiopathic central early puberty: in 3 girls the appearance of pubertal signs started before the age of $9 \mathrm{yr}$ and in 4 girls before the age of $10 \mathrm{yr}$. Two girls had organic CPP: one had a meningomyelocele and the other a hydrocephalus with a start of puberty before the age of respectively 9 and 8 yr. Median age at start of treatment was $8.7 \mathrm{yr}$ (range 2.8 to 10.8). All patients received therapy with depot leuprolide-acetate $3.75 \mathrm{mg}$ (Lucrin depot, Abbott, Amsterdam, The Netherlands) given subcutaneously every 4 weeks. During the first month it was given every 2 weeks. Puberty suppression was evaluated by clinical evaluation, repeating 
GnRH stimulation test after 3 months, by measuring basal serum levels of LH, follicle stimulating hormone and estradiol/testosterone every 6 months, and bone age assessment. All children had complete suppression of plasma concentrations of LH and follicle stimulating hormone during the GnRH test after 3 months of treatment (levels below $5 \mathrm{IU} / \mathrm{L}$ ). During treatment with GnRH all children except one girl had basal sex steroids concentrations equal or less than prepubertal levels (estradiol below $50 \mathrm{pmol} / \mathrm{L}$, testosterone below $1 \mathrm{nmol} / \mathrm{L}$ ). In the girl with incomplete suppression the dose of leuprolide-acetate was doubled. In the first year the mean ratio of the change of bone age and change of chronological age was 0.72 and in the second year, 0.47.

Thirty-four patients had baseline and half-year measurements, 33 of them had 1-yr measurements and 16 children (15 girls and 1 boy) had 2 -yr follow-up. One girl stopped treatment after 6 months, and one stopped after $1 \mathrm{yr}$. The other children are still included in this ongoing study. No BMD sD for chronological age could be calculated for 1 girl, $2.8 \mathrm{yr}$ old, because our reference data start from the age of $4 \mathrm{yr}$. Her data could be used in the evaluation of BMD SD calculated for bone age.

\section{Methods}

Anthropometry, BMD, and body composition measurements and assessment of biochemical bone parameters were performed at baseline and during $\mathrm{GnRH}$ treatment for 6 months, $1 \mathrm{yr}$, and $2 \mathrm{yr}$. Height was measured with a Harpenden stadiometer (Holtain Ltd., Crymmyth, UK). Height was compared with age- and sex-matched reference values (15) and expressed as SD score (SDS). Body mass index was calculated as weight/(height $)^{2}$ $\left(\mathrm{kg} / \mathrm{m}^{2}\right)$ and compared with age- and sex-matched reference values (16) and expressed as SDS. Pubertal development was determined according to Tanner (17).

BMD $\left(\mathrm{g} / \mathrm{cm}^{2}\right)$ of the lumbar spine and total body was measured by dual-energy x-ray absorptiometry (DXA) (Lunar, DPXL/PED, Lunar Radiation Corporation, Madison, WI). The coefficient of variation has been reported as $1.04 \%$ for lumbar spine and $0.64 \%$ for total body (18). The coefficient of variation (SD) for lumbar spine in our setting is 1.1 $(0.2) \%$. Ancillary DXA-derived data were used to calculate lumbar spine volumetric BMD [bone mineral apparent density (BMAD)] with the model BMAD $=$ BMD $\times[4 /(\pi \times$ width $)]$, as validated before $(19)$. BMD and BMAD results were compared with our age- and sex-matched Dutch reference values (2) and expressed as SDS. With the total body measurement by DXA, the body composition was measured as lean tissue mass, fat mass, and bone mineral content. The coefficients of variation have been reported as $2.2 \%$ for fat mass, $1.1 \%$ for lean tissue mass, and $0.6 \%$ for bone mineral content (18). Bone mineral content, lean tissue mass, fat mass, and percentage body fat were compared with our ageand sex-matched Dutch reference values and expressed as SDS (3).

Bone age was assessed by one investigator using an x-ray of the left hand, according to the Greulich and Pyle method (20), at baseline in 34 patients, after 6 months in 21 patients, after $1 \mathrm{yr}$ in 32 patients, and after $2 \mathrm{yr}$ in 16 patients.

Blood samples were taken for the assessment of calcium, phosphate, alkaline phosphatase, 1,25 dihydroxyvitamin $\mathrm{D}$, osteocalcin, the carboxyterminal propeptide of type I collagen (PICP), and cross-linked telopeptide of collagen I (ICTP) in the afternoon (between $1330 \mathrm{~h}$ and
1600 h). Samples were not collected on 2 patients at baseline and 2 other patients at 1 yr. Osteocalcin was measured by RIA (Incstar Corporation, Stillwater, ), and 1,25 dihydroxyvitamin D was measured by RIA of Immuno Diagnostic Systems (Boldon, United Kingdom). PICP and ICTP were measured with an RIA kit (Orion Diagnostica, Espoo, Finland). Our own reference values for prepubertal healthy children for osteocalcin, PICP, and ICTP (respectively $n=25, n=82$, and $n=88$ ) were used. In the first morning void of urine, the ratio of hydroxyproline/creatinine $(\mathrm{OHP} /$ creat $)$ and the ratio of calcium/creatinine (CA/creat) were evaluated. Reference values of Wolthers et al. (21) were used for OHP/creat LH and FSH were assessed by RIA (Medgenix, Fleurus, Belgium), and estradiol and testosterone were assessed by RIA of Orion Diagnostica.

\section{Statistical analysis}

One-sample $t$ tests were performed to compare the mean SDS values with normal. We tested to determine whether the average within-patient change differed from zero (with one-sample $t$ test). Pearson correlation coefficient was calculated to test the association between two variables with a normal distribution. Spearman's rank correlation coefficient was used, in case of a nonnormal distribution.

\section{Results}

The results of BMD, BMAD, body composition, height, and body mass index measurements, before and during GnRH treatment, are shown in Table 1.

At baseline, mean lumbar spine BMD SDS was significantly higher than zero, which is the mean SDS of age-and sex-matched healthy controls. Lumbar spine BMD SDS increased during the first 6 months of therapy and decreased between 6 months and $1 \mathrm{yr}$ of treatment $(P<0.01)$. After 2 yr, lumbar spine BMD SDS was not significantly different from normal. Mean lumbar spine BMAD SDS and total body BMD SDS were not significantly different from normal at baseline. Lumbar spine BMAD SDS showed a transient increase after 6 months of treatment. Total body BMD SDS remained stable during treatment.

Mean total body bone mineral content SDS, lean tissue mass SDS, fat mass SDS, and percentage body fat SDS were significantly higher than zero at baseline. Total body bone mineral content SDS had increased after 6 months and $1 \mathrm{yr}$ of treatment, compared with baseline. Lean tissue mass SDS decreased significantly during treatment, whereas fat mass SDS and percentage body fat SDS increased.

Mean height SDS and body mass index SDS were higher than zero at baseline. Mean height SDS had decreased after 2 yr of treatment. Body mass index SDS increased during treatment.

TABLE 1. Mean (SD) of variables at baseline and during treatment with GnRH (Rx) in children with CPP

\begin{tabular}{lcccc}
\hline & Baseline & 6-months Rx & 1-yr Rx & \multicolumn{1}{c}{2 -yr Rx } \\
\hline & $\mathrm{n}=33$ & $\mathrm{n}=33$ & $\mathrm{n}=32$ & $\mathrm{n}=16$ \\
Lumbar spine BMD SDS & $0.51(1.14)^{3}$ & $0.72(1.04)^{1, b}$ & $0.53(1.04)^{3}$ & $0.11(0.81)$ \\
Lumbar spine BMAD SDS & $0.18(1.21)$ & $0.42(1.10)^{4, c}$ & $0.30(1.24)$ & $-0.01(1.04)$ \\
Total body BMD SDS & $0.09(1.21)$ & $0.24(1.27)$ & $0.35(1.08)$ & $0.16(0.72)$ \\
Total body BMC SDS & $0.60(1.17)^{2}$ & $0.83(1.13)^{1, c}$ & $0.88(1.17)^{1, d}$ & $0.70(1.17)^{4}$ \\
Lean tissue mass SDS & $0.91(1.19)^{1}$ & $0.74(1.10)^{1, b}$ & $0.67(1.10)^{2, b}$ & $0.33(1.27)^{b}$ \\
Fat mass SDS & $0.38(0.89)^{4}$ & $0.76(0.94)^{1, a}$ & $0.98(0.93)^{1, a}$ & $1.02(1.13)^{2, b}$ \\
\% Body fat SDS & $0.44(1.09)^{4}$ & $0.96(1.15)^{1, a}$ & $1.24(1.09)^{1, a}$ & $1.39(1.36)^{1, a}$ \\
Height SDS & $1.08(1.20)^{1}$ & $1.09(1.15)^{1}$ & $0.97(1.19)^{1}$ & $0.77(1.21)^{4, d}$ \\
Body mass index SDS & $0.96(1.12)^{1}$ & $1.16(1.12)^{1, c}$ & $1.38(1.11)^{1, a}$ & $1.37(1.21)^{1, c}$ \\
\hline
\end{tabular}

BMD, bone mineral density $\left(\mathrm{g} / \mathrm{cm}^{2}\right)$; BMAD, bone mineral apparent density $\left(\mathrm{g} / \mathrm{cm}^{3}\right)$; BMC, bone mineral content (g); SDS, SD score. The mean SDS was compared with normal, and the within-patient change from baseline was tested.

${ }^{1} P<0.001,{ }^{2} P<0.01,{ }^{3} P<0.02,{ }^{4} P<0.05$ higher than zero.

${ }^{a} P<0.001,{ }^{b} P<0.01,{ }^{c} P<0.02,{ }^{d} P<0.05$ vs. baseline. 
The two boys did not have lumbar spine BMD SDS higher than zero at baseline. During treatment, all the variables showed the same pattern as that seen in the girls.

When SDS was calculated for bone age instead of chronological age $\left(\mathrm{SDS}_{\mathrm{BA}}\right)$, mean lumbar spine $\mathrm{BMD} \mathrm{SDS}_{\mathrm{BA}}$ was -0.82 (sD 0.91), mean BMAD SDS BA $_{\text {B }}$ was -0.46 (sD 1.11), and mean total body BMD SDS BA $_{\text {B }}$ was -1.07 (SD 1.05) at baseline, all significantly lower than zero (lumbar spine and total body BMD $P<0.001$, BMAD $P<0.05)$. Mean lumbar spine BMD and BMAD SDS BA $_{\mathrm{BA}}$ and total body BMD SDS $\mathrm{BA}_{\mathrm{BA}}$, after 2 yr of treatment, were still significantly lower than zero (lumbar spine BMD $P<0.001$, total body BMD $P<0.01$, BMAD $P<$ $0.05)$ and did not differ significantly from baseline.

The results of biochemical markers of bone metabolism are shown in Table 2. Mean osteocalcin, PICP, and ICTP at baseline were significantly higher than those of prepubertal controls (all $P<0.001$ ). These values and alkaline phosphatase had decreased after 6 months. Mean PICP and ICTP at 6 months and osteocalcin at 12 months were not significantly different from those of prepubertal controls. Urine CA/creat had increased after 6 months, and OHP/creat had diminished after 1 yr. Serum calcium and phosphate were normal at baseline and did not change significantly during time.

At baseline, lumbar spine BMD SDS correlated with lean tissue mass SDS $(r=0.46, P<0.01)$ and body mass index SDS $(\mathrm{r}=0.46, P<0.01)$. Total body BMD SDS correlated with fat mass SDS $(r=0.44, P<0.02)$, percentage body fat SDS $(r=$ $0.37, P<0.02)$, and body mass index SDS $(r=0.42, P<0.02)$. Height SDS, Tanner stage, or biochemical bone parameters were not related to lumbar spine BMD or BMAD or total body BMD SDS. Height SDS correlated with lean tissue mass SDS $(r=0.76, P<0.001)$ and total body bone mineral content SDS $(\mathrm{r}=0.58, P<0.001)$.

The change between baseline and 2-yr treatment of height SDS correlated with the change in lumbar spine BMD SDS $(\mathrm{r}=0.57, P<0.05)$, the change in lean tissue mass SDS $(\mathrm{r}=$ $0.77, P<0.001)$, and the change in bone mineral content SDS $(\mathrm{r}=0.69, P<0.01)$, and not with the change in total body BMD SDS or lumbar spine BMAD SDS. The change in levels of biochemical markers of bone turnover did not correlate with the change of BMD or BMAD SDS or height SDS.

\section{Discussion}

In children with CPP, mean lumbar spine BMD was high, and spinal BMAD and total body BMD were normal for chronological age. After 2 yr of treatment with $\mathrm{GnRH}$, mean lumbar spine BMD and BMAD and total body BMD were normal. Lumbar spine BMD and BMAD and total body BMD for bone age were low, before and after 2 yr of treatment with GnRH. During treatment, fat mass and percentage body fat SDS increased, whereas lean tissue mass SDS decreased. Biochemical markers of bone formation and of bone resorption decreased.

Previous studies reported increased lumbar spine (measured with DXA) or radius (measured with single photon absorptiometry) BMD for chronological age, but appropriate for bone age in girls with CPP (10-12). The higher spinal $\mathrm{BMD}$ at baseline is in agreement with our findings, but we found decreased BMD for bone age. The discrepancy may be caused by differences in reference values, differences in assessment of bone age, or differences in timing of start of treatment. In the present study, reference values of a large cohort of healthy children, of the same population and measured on the same DXA apparatus, were used.

Mean spinal BMAD (corrected for estimated bone volume) was not increased. BMD is an areal density and does not adjust for bone size completely. Therefore, the high spinal BMD could be caused by an increase of bone size.

During puberty, estrogens and GH play an important role in bone mineralization and bone metabolism in girls. In early puberty, low levels of estradiol stimulate growth and $\mathrm{GH}$ production. A significant increase of $\mathrm{GH}$ is seen during early puberty, with maximal levels at stage III in girls (22). Bone modeling of new bone and bone remodeling of existing mineralized tissue are each ongoing processes in growing children. The biochemical markers are not specific for either the process of bone modeling or remodeling (23). Markers of bone metabolism are related to growth velocity and increase maximally during midpuberty $(24,25)$. From stage III to $\mathrm{V}$ (late puberty), estradiol levels increase significantly, GH levels decrease, and markers of bone formation and markers of bone resorption decrease (26). In postmenopausal women and in adults treated with $\mathrm{GnRH}$, the decline of estrogens is associated with an increase of bone turnover, the opposite of what happens during late puberty $(13,14)$. At baseline, the

TABLE 2. Mean (SD) of biochemical parameters at baseline and during GnRH (Rx) in children with CPP

\begin{tabular}{|c|c|c|c|c|c|}
\hline & Baseline & 6 months $\mathrm{Rx}$ & 1 year $\mathrm{Rx}$ & 2 years $R x$ & Reference values \\
\hline & $\mathrm{n}=32$ & $\mathrm{n}=32$ & $\mathrm{n}=30$ & $\mathrm{n}=16$ & \\
\hline Osteocalcin $(\mu \mathrm{g} / \mathrm{L})$ & $23.5(7.0)$ & $19.0(5.3)^{a}$ & $15.7(3.8)^{b}$ & $16.3(3.3)^{b}$ & $4-20$ \\
\hline $\operatorname{PICP}(\mu \mathrm{g} / \mathrm{L})$ & $494(190)$ & $321(141)^{b}$ & $335(123)^{b}$ & $276(84)^{b}$ & $77-626$ \\
\hline $\operatorname{ICTP}(\mu \mathrm{g} / \mathrm{L})$ & $18.3(4.0)$ & $12.8(2.5)^{b}$ & $12.0(4.3)^{b}$ & $11.5(2.6)^{b}$ & $6-19$ \\
\hline Alk. phosphatase (U/L) & $291(73)$ & $217(47)^{b}$ & $221(53)^{b}$ & $205(55)^{b}$ & $80-225$ \\
\hline $1,25 \mathrm{OHD}(\mathrm{pmol} / \mathrm{L})$ & $136(47)$ & $129(52)$ & $119(42)$ & $123(28)$ & $39-102$ \\
\hline Urine OHP/creat (mg/g) & $122(56)$ & $107(115)$ & $76(31)^{a}$ & $67(27)$ & $17-145$ \\
\hline Urine CA/creat & $0.20(0.13)$ & $0.40(0.28)^{c}$ & $0.25(0.16)$ & $0.31(0.18)^{a}$ & \\
\hline
\end{tabular}

PICP, carboxy terminal propeptide of type I collagen; ICTP, cross-linked telopeptide of type I collagen; Alk. phosphatase, alkaline phosphatase; 1,25 OHD, 1,25 dihydroxyvitamin D; OHP/creat and Ca/creat, hydroxyprolin/creatinine and calcium/creatinine (mmol/L per mmol/L) ratio's in first morning void of urine. The mean within patient change from baseline was tested.

${ }^{a} P<0.01$.

${ }^{b} P<0.001$.

${ }^{c} P<0.02$.

${ }^{d} P<0.05$ vs. baseline. 
patients had bone turnover comparable with that of adolescents in early puberty. Bone formation and bone resorption markers were higher than prepubertal values, probably because of the increased growth related to early puberty. The markers of bone turnover decreased to prepubertal levels during treatment. This mainly reflects a decrease in bone modeling.

Increased $\mathrm{GH}$ and/or estrogens levels, associated with early puberty, may have caused the increase of lumbar spine BMD at baseline in the girls. Lumbar spine consists of more trabecular bone than bone of the total body, which is for $80 \%$ cortical bone (27). Bone turnover is higher in trabecular bone (28), which may explain the differences found between lumbar spine and total body BMD. Also, in postmenopausal women, change in BMD is faster in trabecular bone than in cortical bone (29). The initial increase of lumbar spine BMD and BMAD SDS may be explained by incomplete suppression of puberty during the first months. The decrease in spinal BMD, thereafter, is probably caused by the decline of estrogens and GH. A decrease in nocturnal GH secretion and subnormal response to GH stimulation tests were described after 3-12 months treatment with GnRH in children with CPP $(10,30-32)$. However, no relation was found between the subnormal GH levels and growth velocity during treatment with $\mathrm{GnRH}$ (32). The decline of GH may explain the decrease of lean tissue mass SDS and the increase of fat mass and percentage fat SDS. GH is known to have lipolytic and anabolic effects. Children and adults with GH deficiency have decreased lean tissue mass and increased fat mass, which improve during treatment (33-36).

In conclusion, children with CPP have normal BMD for chronological age but decreased BMD, for bone age, after 2 yr of treatment with GnRH. Puberty is an important period for bone accretion. In patients with CPP, pubertal development is temporarily inhibited by GnRH. It is unknown whether BMD increases normally after cessation of GnRH and whether the patients reach a normal peak bone mass. Long-term longitudinal studies, till peak bone mass is achieved, are needed to evaluate BMD and body composition after cessation of treatment.

\section{Acknowledgments}

The authors thank Jopie Hensen, of the Department of Nuclear Medicine, for her assistance in DXA measurements; Manon van Paasen, Sophie Dumas, and Ingrid Beukers (of the out-patient department); Dick Mul, for the bone age assessments; and Melanie Engels for her assistance in data collection.

\section{References}

1. Bonjour JP, Theintz G, Buchs B, Slosman D, Rizzoli R. 1991 Critical years and stages of puberty for spinal and femoral bone mass accumulation during adolescence. J Clin Endocrinol Metab. 73:555-563.

2. Boot AM, de Ridder MAJ, Pols HAP, Krenning EP, de Muinck KeizerSchrama SMPF. 1997 Bone mineral density in children and adolescents: relation to puberty, calcium intake and physical activity. J Clin Endocrinol Metab. 82:57-62.

3. Boot AM, Bouquet J, de Ridder MAJ, Krenning EP, de Muinck Keizer-Schrama SMPF. 1997 Determinants of body composition, measured by dual energy x-ray absorptiometry in Dutch children and adolescents. Am J Clin Nutr. 66.232-238.

4. Rico H, Revilla M, Villa LF, Hernandez ER, Alvarez de Buergo M, Villa M. 1993 Body composition in children and Tanner's stages: a study with dual energy x-ray absorptiometry. Metabolism. 42:967-970.

5. Sigurjonsdottir IJ, Hayles AB. 1968 Precocious puberty: a report of 96 cases. Am J Dis Child. 115:309-321.

6. Kauli R, Galatzer A, Kornreich L, Lazar L, Pertzelan A, Laron Z. 1997 Final height of girls with central precocious puberty, untreated $v$ s. treated with cyproterone acetate or GnRH analogue. Horm Res. 47:54-61.
7. Oostdijk W, Rikken B, Schreuder S, et al. 1996 Final height in central precocious puberty after long-term treatment with a slow-release $\mathrm{GnRH}$ agonis Arch Dis Child. 75:292-297.

8. Paul D, Conte FA, Grumbach MM, Kaplan SL. 1995 Long term effect of gonadotropin-releasing hormone on final and near-final height in 26 children with true precocious puberty treated at a median age of less than 5 years. J Clin Endocrinol Metab. 80:546-551.

9. Kletter GB, Kelch RP. 1994 Effects of gonadotropin-releasing hormone analog therapy on adult stature in precocious puberty. J Clin Endocrinol Metab. 79:331-334

10. Antoniazzi F, Bertoldo F, Zamboni G, et al. 1995 Bone mineral metabolism in girls with precocious puberty during gonadotrophin-releasing hormone agonist treatment. Eur J Endocrinol. 133:412-417.

11. Saggese G, Beretlloni S, Baroncelli GI, Battini R, Franchi G. 1993 Reduction of bone density: an effect of gonadotropin releasing hormone analogue treatment in central precocious puberty. Eur J Pediatr. 152:717-720.

12. Neely EK, Bachrach LK, Hintz RL, et al. 1995 Bone mineral density during treatment of central precocious puberty. J Pediatr. 127:819-822.

13. Johansen JS, Riis BJ, Hassager C, Moen M, Jacobson J, Christiansen C. 1988 The effect of a gonadotropin-releasing hormone agonist analog on bone metabolism. J Clin Endocrinol Metab. 67:701-706.

14. Goldray D, Weisman Y, Jaccard N, Merdler C, Chen J, Matzkin H. 1993 Decreased bone density in elderly mean treated with the gonadotropin-releasing hormone agonist decapeptyl. J Clin Endocrinol Metab 76:288-290.

15. Roede MJ, van Wieringen JC. 1985 Growth diagrams 1980, Netherlands. Third nationwide survey. T Soc Gezondheidszorg. 63:1-34.

16. Weststrate JA, Deurenberg P, Van Tinteren H. 1989 Body fat distribution and adiposity indices in Dutch children 0-18 year age. Int J Obes. 13:465-477.

17. Tanner JM, Whitehouse R. 1976 Longitudinal standards for height, weightheight, weight-velocity and stages of puberty. Arch Dis Child. 51:170-179.

18. Johnson J, Dawson Hughes B. 1991 Precision and stability of dual energy x-ray absorptiometry measurements. Calcif Tissue Int. 49:174-178.

19. Kröger H, Vainio P, Nieminen J, Kotamieni A. 1995 Comparison of different models for interpreting bone mineral density measurements using DXA and MRI technology. Bone. 17:157-159.

20. Greulich WW, Pyle SI. 1959 Radiographic atlas of skeletal development of the hand and wrist. 2nd ed. Standford; Standford University Press.

21. Wolthers OD, Riis BJ, Pedersen S. 1993 Bone turnover in asthmatic children with oral prednisolone or inhaled budesonide. Pediatr Pulmonol. 16:341-346.

22. Albertsson-Wikland K, Rosberg S, Karlberg J, Groth T. 1994 Analysis of 24-hour growth hormone profiles in healthy boys and girls of normal stature: relation to puberty. J Clin Endocrinol Metab. 78:1195-1201.

23. Salusky IB, Goodman WG. 1995 Growth hormone and calcitriol as modifier of bone formation in renal osteodystrophy. Kidney Int. 48:657-665.

24. Calvo MS, Eyre DR, Gundberg CM. 1996 Molecular basis and clinical application of biological markers of bone turnover. Endocr Rev. 17:333-368.

25. Hertel NT, Stoltenberg M, Juul A, et al. 1993 Serum concentrations of type I and III procollagen propeptides in healthy children and girls with central precocious puberty during treatment with gonadotropin-releasing hormone analog and cyproterone acetate. J Clin Endocrinol Metab. 76:924-927.

26. Bluhmsohn A, Hannon RA, Wrate R, et al. 1994 Biochemical markers of bone turnover in girls during puberty. Clin Endocrinol (Oxf). 40:663-670.

27. Martin TJ, Ng KW, Nicholson GC. 1988 Cell biology of bone. Baillieres Clin Endocrinol Metab. 2:1-29.

28. Dempster DW, Lindsay R. 1993 Pathogenesis of osteoporosis. Lancet. 341:797-805.

29. Riggs BL, Wahner HW, Dunn WL, Mazess RB, Offord KP, Melton LJ. 1981 Differential changes in bone mineral density of the appendicular and axial skeleton with aging. J Clin Invest. 67:328-335.

30. DiMartino-Nardi J Wu R, Varner R, Wong WLT, Saenger P. 1994 The effect of luteinizing hormone-releasing hormone analog for central precocious puberty on growth hormone $(\mathrm{GH})$ and $\mathrm{GH}$-binding protein. J Clin Endocrinol Metab. 78:664-668

31. Mansfield MJ, Rudlin CR, Crigler JF, et al. 1988 Changes in growth and serum growth hormone and plasma somatomedin-C levels during suppression of gonadal sex steroid secretion in girls with central precocious puberty. J Clin Endocrinol Metab. 66:3-9.

32. Kamp GA, Manasco PK, Barnes KM, et al. 1991 Low growth hormone levels are related to increased body mass index and do not reflect impaired growth in luteinizing hormone-releasing hormone agonist-treated children with precocious puberty. J Clin Endocrinol Metab. 72:301-307.

33. Amato G, Carella C, Fazio S, et al. 1993 Body composition, bone metabolism, and heart structure and function in growth hormone $(\mathrm{GH})$-deficient adult before and after GH replacement therapy at low doses. J Clin Endocrinol Metab. 77:1671-1676.

34. Leger J, Carel C, Legrand I, Paulsen A, Hassan M, Czernichow P. 1994 Magnetic resonance evaluation of adipose tissue and muscle tissue mass in children with growth hormone (GH) deficiency, Turner's syndrome, and intrauterine growth retardation during the first year of treatment with $\mathrm{GH}$. J Clin Endocrinol Metab. 78.904-909.

35. Boot AM, Engels ME, Boerma GJM, Krenning EP, de Muinck KeizerSchrama SMPF. 1997 Changes in bone mineral density, body composition, and lipid metabolism during growth hormone $(\mathrm{GH})$ treatment in children with $\mathrm{GH}$ deficiency. J Clin Endocrinol Metab. 82:2423-2428.

36. Binnerts A, Swart GR, Wilson JHP, et al. 1992 The effect of GH administration in $\mathrm{GH}$ deficient adults on bone, protein, carbohydrate, and lipid homeostasis, as well as on body composition. Clin Endocrinol (Oxf). 37:79-87. 